\title{
Qualidade das interações entre professor e alunos na sala de aula de língua estrangeira
}

\author{
Andreza Jesus Meireles (MEIRELES, Andreza J.) \\ Mestre pela Universidade de Brasília - UnB \\ andrezamei@gmail.com
}

José Carlos Paes de Almeida Filho (ALMEIDA FILHO, José Carlos P.)

Professor Doutor da Universidade de Brasília - UnB

jcpaes@unb.br

\section{Resumo}

Este trabalho ${ }^{1}$ trata da análise da qualidade das interações entre professor(a) e alunos numa sala de aula de Língua Estrangeira (Inglês). A turma que acompanhamos tem faixa etária entre 11 e 12 anos e cursa, no momento da pesquisa, o $6^{\circ}$ ano do Ensino Fundamental. Essa escola tem um diferencial: o ensino de línguas é terceirizado, isto é, um instituto de idiomas é contratado especificamente para ensinar inglês. Com o intuito de realizar esta pesquisa, após observarmos e gravarmos quatro aulas da professora participante da pesquisa, selecionamos uma aula "típica" e analisamos os tipos de interações presentes e sua qualidade. A análise que fizemos contou com anotações de campo, com uma entrevista junto à professora e com a transcrição das aulas observadas. Assim, esta pesquisa de natureza qualitativa — um estudo de caso — e de caráter interpretativista, visa revelar os tipos de interação flagrados no contexto em foco, bem como suas qualidades relativas. Os turnos, na sua grande maioria produzidos na línguaalvo, caracterizaram-se por serem massivamente do tipo IRA (iniciação-respostaavaliação), típico de uma relação formal focada no estudo da forma da língua. As interações soam engessadas, pré-fabricadas, resultando num envolvimento precário dos aprendizes com poucas chances de aquisição.

Palavras-chave: qualidade, tipos de interação, ensino de línguas.

\begin{abstract}
This article deals with the quality of observed interactions between a teacher of a foreign language (English) and her 11 to 12 year-old students in one particular sixth grade class of a private language school. This teaching situation consists of elementary school students being taught a foreign language (FL) at their school through a special third- party contract. In order to accomplish this study, four lessons of the class teacher were observed and recorded. A typical lesson was then selected for analysis. This

1 O presente artigo é fruto de pesquisa realizada no Programa de Iniciação Científica (PIC) da Universidade de Brasília, tendo sido concluído no ano de 2008. Este trabalho foi também apresentado no X Seminário de Linguística Aplicada, na UFBA, em dezembro de 2008 com o apoio do PPGLA da UnB. Especiais agradecimentos à professora observada que nos possibilitou realizar este estudo.
\end{abstract}


lesson was finally transcribed among the recorded ones so that an analysis of the types of interaction could be conducted. The interpretation of the registered interactions was aided by notes made from direct observations in class, and an interview with the class teacher. This qualitative interpretative research is actually a case study meant to explore the types of interaction produced during the lesson according to particular qualities inherent in the exchanges. The turns recorded, the majority of which in the target language (English), are characterized by the classical IRE model (initiation, response, evaluation), which is typical of a formal pedagogical relationship enabled by the study of language usage rather than use. The prefabricated interactions sound artificial, with insufficient motivation and scant opportunities for acquisition of the target language.

Keywords: quality, types of interaction, FL teaching.

\section{Introdução}

Este artigo trata da qualidade das interações entre professor e aluno numa sala de aula de língua estrangeira. Objetivamos com o mesmo dar continuidade aos estudos relativos à aquisição de uma língua estrangeira e mostrar como a qualidade da interação que ocorre dentro de sala de aula é fundamental para o desenvolvimento da competência comunicativa dos alunos, meta principal do ensino de línguas ${ }^{2}$. Visto que analisaremos a qualidade das interações na sala de aula de língua estrangeira (LE), faz-se necessário mencionar a importância da interação tanto na aquisição de linguagem como no aprendizado escolar de novas línguas.

Nosso foco é a qualidade da interação e partimos do pressuposto de que "a interação não é algo que o professor decide colocar ou não em sua prática, mas que é algo inerente à noção de pedagogia da sala de aula" (ALLWRIGHT, 1984 apud MOURA, 2005, p. 30). Também concordamos que a interação é uma das peças-chave para a "sala de aula como ambiente para a aprendizagem" (ALMEIDA FILHO\& BARBIRATO, 2000; BARBIRATO, 2005). Dessa forma, pretendemos analisar os tipos de interações que ocorrem dentro desse espaço. O pressuposto que estaremos analisando é o de que quanto mais relevantes forem as aulas e interações, maiores serão as chances de o aprendizado duradouro ou aquisição ocorrer. Além disso, através da troca de experiências pessoais, de impressões e de discussões entre estudantes, o ensino deixa de ser algo tão somente descritivo e torna-se algo maior: uma nova janela para a expressão

\footnotetext{
${ }^{2}$ Estamos tomando competência comunicativa no sentido de uma capacidade de mobilizar e articular conhecimentos sobre o funcionamento de uma língua e de comunicação nela, capacidade de ação linguageira adequada ao contexto de uso e sob certas atitudes.
} 
de pensamentos, opiniões e argumentos envolvendo o eu dos aprendizes. Com esta nova possibilidade, as interações presentes terão mais qualidade quando comparadas a tradicionais modelos de interação presentes na maioria das escolas de línguas. Barbirato (2005, p.30) delineia a relevância da interação na aquisição de uma LE ao defini-la como:

(...) um processo de negociação de significados, um processo colaborativo para se alcançar propósitos comunicativos. Nesse processo de buscar interagir, o aprendiz pode desenvolver suas habilidades lingüísticas de maneira mais profunda e duradoura uma vez que ele se encontra engajado num processo de construção (e desconstrução) de significados.

Dentro dessa visão, o aprendiz deixa de ser uma figura passiva no processo de aprendizagem e passa a ter um posicionamento decisivo para o desenvolvimento de suas competências. A mesma autora (BARBIRATO, ibid., p.27) reconhece a interação como “oportunidades para os aprendizes produzirem, criarem e se desenvolverem na línguaalvo como sujeitos ativos do processo". A partir "[...] de trocas estabelecidas com seu meio sociocultural, o indivíduo se constitui e se desenvolve" (BASSI e DUTRA, 2004). Seja através de negociações, diálogos ou de discussões, a interação promove o compartilhamento de conhecimento e experiências entre os aprendizes, o que promove um ambiente propício para a aquisição de uma LE. Esse posicionamento mais ativo pode ocorrer como consequência dos "empecilhos que geram oportunidades de negociação de suas mensagens" (CÂNDIDO JÚNIOR, 2004). Segundo Cândido Júnior, essas oportunidades de negociação seriam "esforços feitos pelos falantes no sentido de compreender e de serem compreendidos" (idem).

De acordo com Almeida Filho (2001:1) "a interação sempre foi, desde Sócrates, que já usava o método da pergunta e resposta para seus ensinamentos (com forte traço de oralidade), um procedimento amplamente utilizado no âmbito da educação escolar". Conforme Allwright (1984, apud BARBIRATO, op.cit., p.49), a "interação é um aspecto do qual não se pode escapar e um ponto inescapavelmente crucial da vida da sala de aula". Assim, a interação é parte constitutiva da aula; no entanto, a qualidade dessas interações não é sempre a mesma, variando consideravelmente nos contextos em que as interações ocorrem. Ao analisar interações observadas em aulas convencionais de línguas, pode-se encontrar um tipo básico de interação reconhecível como artificial, mecânica, descontextualizada, calcada na forma e diferentes das interações que os alunos 
encontram fora da sala de aula.

Ao observar o cenário de ensino/aprendizagem de LE de muitas escolas brasileiras, podemos reconhecer que as experiências de ensinar LE se colocam freqüentemente como inescapavelmente artificiais e abordam tópicos fúteis e/ou "dos outros" ${ }^{3}$. Ou seja, desconsideram-se as experiências vividas pelos próprios alunos e as contribuições que estes poderiam trazer para a aquisição de uma LE ao tornar o aprendizado significativo, por remontar ao universo do aprendiz.

Podemos considerar dois tipos de interação presentes nas aulas de LE: o primeiro seria na língua-alvo, enquanto que o outro tipo seria na língua materna (LM). Segundo Almeida Filho (2004), o primeiro tipo refere-se às interações premeditadas pelo professor ou pelo autor do livro didático, já o segundo tipo representa falas institucionais (avisos), ecos do livro didático (leitura em voz alta, cópia na lousa) e falas paralelas (casos pessoais, comentários sobre outros assuntos alheios à disciplina).

Desta forma, constata-se que nem toda interação possibilitará um aprendizado bem-sucedido, pois nem toda interação contém a qualidade necessária para servir de insumo para o aprendizado de uma LE. Assim, nosso intuito é produzir uma análise da qualidade de interações ocorridas numa aula típica da professora observada, tentando com isso contrastá-la com interações de outros tipos reconhecíveis, entre outros traços, por serem mais significativas para o aprendiz. Barbirato (op.cit., p.38) expõe esse contraste da seguinte forma:

Buscamos hoje, para as aulas de LE um modelo de interação voltado para a construção de significado na língua-alvo na qual professor e alunos trabalham colaborativamente compartilhando significados. Nesse processo, o aprendiz pode participar como sujeito ativo da interação aprendendo a iniciar turnos também e a sustentar uma conversa na língua-alvo. Nesse processo, o aprendiz pode testar hipóteses, aprender a negociar significados e desenvolver sua interlíngua de maneira em parte semelhante àquela em que a criança aprende sua LM. Nesse sentido não tomamos a interação como mera estratégia para aprender a LE. Ela não se resume somente a trocar informações já prontas para praticar estruturas gramaticais.

Vemos, então, que a interação faz parte da constituição de uma aula e que dependendo da sua qualidade, poderá acarretar mais ou menos benefícios para a aquisição da competência comunicativa na língua-alvo. Reafirmamos ainda que nem

\footnotetext{
3“"Dos outros" aqui refere-se a assuntos que não fazem parte da realidade dos estudantes (ALMEIDA FILHO, 2004).
} 
toda interação ocorrida na sala de aula de LE terá relevância para o aprendizado da língua-alvo. Por outro lado, interações que se baseiem nas experiências e conhecimentos prévios dos aprendizes e que ocorram crescentemente na própria LE trazem em si um potencial maior para serem aproveitadas no processo de aquisição da nova língua. Por conta dessas disparidades, faz-se necessário um estudo mais circunstanciado da natureza das interações que ocorrem na sala de aula de LE. Ao analisarmos o tipo, a duração e a qualidade das interações presentes neste contexto, tentamos mostrar que essas diferenciações têm repercussão na qualidade das mesmas e essas, no processo aquisicional. Partindo do pressuposto de que qualidade — além de quantidade - é o fator de diferenciação mais destacado nas salas, seguiremos agora com o aporte teórico que fundamenta este estudo.

\section{Pressupostos teóricos}

A sala de aula é o espaço de experiências com e na língua-alvo por excelência no aprendizado de línguas. Segundo Barbirato (2001) a sala de aula convencional representa “o contexto sistemático de ensino/aprendizagem racional de línguas. Nesse contexto o aprendiz é exposto a uma sequência de aulas as quais acabam sendo, na maioria das vezes, a única fonte de insumo controlado para a aprendizagem”. Em virtude do papel que a sala de aula desempenha na aquisição da LE, visto que ela é "um lugar de construção de conhecimentos, um ambiente para que a aquisição ocorra" (BARBIRATO, op. cit., p.58) e "na maioria das vezes, o único contato com a nova língua", as atividades propostas pelo professor são de extrema importância para a maximização desse potencial.

Para Ellis (2003, apud BARBIRATO, ibid., p. 47), a sala de aula é um lugar onde as pessoas se socializam e aprendem, porém em muitas salas de aulas as trocas sociais não são incentivadas. Esse é o caso do contexto analisado. Aqui os alunos não são instados a trocarem suas experiências uns com os outros e acabam ficando limitados às repetições de falas alheias que não têm vínculo algum com suas experiências de vida.

Prabhu (2001) define a aula como "uma unidade numa sequência curricular planejada" e por uma rotina estável. O linguista aplicado indiano também afirma que a aula também pode ser vista como a "implementação de um método". De acordo com Barbirato (ibid., p.59): 
A plasmagem de um método implica de maneira geral um padrão préespecificado de atividades dentro de uma aula (ou sequência de aulas). Assim, é o método que determina o plano de aula e a escolha pelo professor das atividades e a maneira na qual serão realizadas em sala de aula.

As aulas seguem uma sequência, a qual é definida seja pelo professor, seja pelo autor do livro didático. Conforme mencionado, ela pode ser o resultado de um método, e segue uma rotina: "um ritual pré-determinado de modo geral para toda e qualquer sala de aula e ao qual professores e alunos tentam se adequar e se acomodar dentro deste ritual desempenhando papéis também previamente estabelecidos" (PRABHU, 2001).

Almeida Filho e Barbirato (2000) corroboram que as atividades podem ser divididas em duas categorias (atividades relevantes ao processo de aquisição e atividades irrelevantes ao processo) e as diferencia. Tal classificação será de crucial importância para nossa análise. Eis sua diferenciação:

O termo atividade é um termo mais abrangente e geral e que pode ser subdividido em duas grandes categorias: atividades relevantes ao processo de ensino/ aprendizagem (aquisição) e atividades irrelevantes ao processo. A segunda categoria inclui aqueles tipos de atividades que não têm uma relação direta nem indireta com o ensino/aprendizagem da língua-alvo e por isso não se transformam em insumo para o aprendiz. Essas atividades são geralmente realizadas na LM do aluno, sem com isso queremos implicar que tudo que for realizado na LM é irrelevante e tudo que for produzido na língua-alvo é relevante (grifo dos autores).

Segundo Barbirato (op.cit., p.43), nas interações que predominam o modelo IRA (iniciação - resposta- avaliação), há poucas oportunidades para os aprendizes testarem a competência produtiva, sendo que as oportunidades de interação disponíveis se restringem a responder às perguntas formuladas pelo professor.

Além disso, pela forma como o aluno adquire a LE, ao usar esta aprendizagem em situações genuinamente comunicativas, o aluno tem de fazer um grande deslocamento (BARBIRATO, op.cit., p.48) a fim de utilizar a língua-alvo em contextos comunicativos reais.

De acordo com a autora, "o papel do aluno [nesse contexto] se limita a repetir, completar turnos modelados pelo professor, responder a perguntas pedagógicas verificadoras de aprendizagem de estruturas". A interação no contexto observado é bem 
ilustrada nas palavras de Almeida Filho (2004) “como imprópria para promover processos bem sucedidos de aprender e ensinar LE". As interações presentes nas aulas observadas revelam o seu caráter tradicionalista. Almeida Filho (mimeo, 2006) postula que as interações presentes nas aulas de LE estão limitadas a "um fazer preso a imitações, repetições, modelações, complementos e conversões".

As interações que caracterizaram as aulas analisadas foram "interações explicitadoras disfarçadas de comunicação" " ${ }^{4}$. Barbirato (2005, p. 41) define tais interações de acordo com as características elencadas no quadro 2.

Quadro 2: Tipos de interações presentes no contexto observado

Interações explicitadoras disfarçadas de comunicação

- Professor inicia aluno responde.

- Professor avalia a resposta do aluno.

- Interação aluno/aluno.

- Sempre calcada em alguma estrutura gramatical específica disfarçada num contexto.

- Respostas previamente estabelecidas.

- Controle sobre a linguagem a ser utilizada.

Baseado em de Barbirato (2005).

O quadro 2 ilustra as principais interações presentes no contexto analisado. Tais interações são marcadas pela iniciação da professora nos turnos de fala, seguidas das respostas dos alunos que são avaliadas pela professora regente. As interações partem de uma estrutura gramatical, que é apresentada de forma contextualizada. Com o intuito de os alunos praticarem esta estrutura, diversas perguntas são feitas pela professora, contudo, as perguntas elaboradas já contêm respostas previamente estabelecidas, tendo em vista que em sua maioria, são perguntas verificadoras da compreensão da estrutura gramatical ou do vocabulário apresentado.

Para a autora, o tipo de interação gerado na sala de aula está diretamente ligado ao papel que o professor de LE desempenha. De acordo com sua definição, o contexto sob análise se encaixaria na abordagem tradicional de ensino:

O professor desempenha o papel de controlador. Dentro desse papel, o professor tem a função de ter o domínio da interação cabendo a ele determinar o que os alunos farão, qual linguagem deve ser usada, como e quando os alunos devem falar. O professor aqui sempre prevê como será a interação e a linguagem que os alunos devem usar. Porém, neste contexto, uma importante característica da interação não

\footnotetext{
${ }^{4}$ Baseado nas propostas de Barbirato (2005) para os diversos tipos de interações.
} 
é observada - a espontaneidade, o uso de linguagem não ensaiada (BARBIRATO, 2005, p. 53, grifo da autora).

Os tipos de interações ocorrentes na aula de língua estrangeira evidenciam a abordagem de ensinar do professor e o papel que desempenha na sala de aula. Almeida Filho (2001) define a abordagem de ensinar como:

(...) o resultado da plasmagem de um conjunto de concepções, sejam elas crenças implícitas ou pressupostos revelados à guisa de hipóteses em alguma configuração específica que a história de vida de cada professor se incumbe de gerar num campo de idéias onde forças outras atuam buscando se impor: idéias de ensinar de outros professores e agentes escolares (orientadores, coordenadores, diretores, pais de alunos) que têm poder nos contextos onde estiverem, as idéias de autores de materiais adotados e de formuladores de exames ou outros tipos de instrumentos de avaliação introduzidos no processo. Incide ainda como força concorrente à da abordagem do professor a concepção de aprender.

As interações listadas no quadro 2 alinham-se ao papel de controlador exercido por professores. Nesse sentido, o professor decide quando o aluno falará, o tema e o quê deve ser dito. Esse tipo de abordagem representa uma abordagem tradicional de ensino.

\section{Metodologia de pesquisa}

A fim de realizarmos esta pesquisa, ficou estabelecido que a observação de aulas de um professor de línguas seria essencial, pois seria a partir delas que faríamos a principal coleta de dados e teríamos elementos para analisar a qualidade das interações presentes. Todavia, faz-se necessário destacar que também foi de nosso interesse registrar e analisar a qualidade dessas interações numa aula que fosse típica do processo construído por aquela professora observada. A aula típica é importante para que possamos ter contato com o que seja o cotidiano daquele professor dentro da sala de aula, para que fiquemos o mais próximo possível do conjunto de aulas do dia a dia dessa turma e longe das "aulas-show" que muitas vezes ocorrem para observador de pesquisa ver.

Assim, os procedimentos adotados para o desenvolvimento desta pesquisa basearam-se na observação de quatro aulas de uma mesma professora de línguas. Essas observações foram gravadas em áudio e notas de campo minuciosas foram 
feitas acerca das aulas. A gravação e as anotações fizeram parte dos dados primários que assim puderam oferecer condições de triangulação de fontes na análise empreendida. A partir do material coletado, elegemos a aula que mais nos pareceu a representante de uma "aula típica" da professora. Dela fizemos a transcrição do material sonoro sobre o qual nos debruçamos a fim de analisarmos a qualidade das interações obtidas nas atividades propostas durante a aula focalizada. Para tornar nosso estudo mais sistêmico e completo, dividimos a aula em atividades e as analisamos individualmente em sequência.

Segundo Moura (2005, p. 77), "a gravação, a transcrição, a descrição e a análise de aulas típicas do dia a dia do professor favorecem a compreensão da abordagem subjacente do professor de línguas". Dessa forma, a partir dessas gravações é possível analisar a abordagem do professor além de seu "autoconceito", do "que diz fazer" e o que realmente faz" (ALMEIDA FILHO, 1993, p.12).

Além da gravação das aulas, foi realizada uma entrevista com a professora regente da turma, por meio da qual buscamos levantar informações sobre a escola, a turma, esclarecer dúvidas quanto a certos procedimentos usados durante as aulas, assim como conhecer sobre a trajetória da regente enquanto professora de línguas, com o intuito de compreendermos melhor sua abordagem.

O contexto de nossa pesquisa foi uma cidade do Distrito Federal, situada numa área privilegiada do Planalto Central. A escola que nos acolheu é particular e nela o ensino de inglês é terceirizado, isto é, a escola contrata um curso de idiomas para que ministre as aulas de inglês aos seus alunos. As aulas de língua estrangeira começam na $1^{\mathrm{a}}$ série e vão até a $8^{\mathrm{a}}$ série $^{5}$ (do Ensino Fundamental) e os professores terceirizados são os responsáveis por elas. No Ensino Médio os alunos passam a ter aulas preparatórias para o vestibular.

Essa iniciativa custa caro à escola: para cada turma são necessários dois professores, pois as turmas são divididas em dois grupos, com no máximo quinze alunos cada. Todavia, a proposta faz com que o ensino de línguas vá além das aulas baseadas em exercícios gramaticais e traduções. A terceirização do ensino de línguas nesta escola traz a vantagem de os alunos entrarem em contato também com a oralidade do idioma, fato esse que não ocorre na maioria das aulas de língua estrangeira do ensino regular.

\footnotetext{
${ }^{5}$ No ano em que esta pesquisa foi realizada (2006) ainda estava em vigor a divisão do Ensino Fundamental em séries.
} 
As aulas acontecem na grade horária dos alunos (ou seja, no mesmo horário das outras disciplinas), duas vezes por semana, sendo que cada uma tem a duração de 50 minutos. Acompanhamos uma turma de 12 estudantes com faixa etária entre $11 \mathrm{e}$ 12 anos de idade cursando a $6^{\mathrm{a}}$ série do Ensino Fundamental. Ao tomarmos por referência a divisão do curso de línguas atuante na escola, esses alunos seriam classificados como sendo do nível básico.

Conforme mencionamos anteriormente, também lançamos mão de uma entrevista feita com a professora. Por meio da entrevista foi possível entender alguns de seus posicionamentos. As perguntas feitas foram em relação à carreira, ao tempo de estudo da língua, como a professora se vê como profissional, a sua abordagem de ensino, se é reflexiva na sua prática pedagógica, se está motivada no seu trabalho, dentre outras. A seguir apresentamos as informações mais relevantes para este trabalho.

A professora que nos recebeu é também a coordenadora do curso de inglês da escola observada. Paula ${ }^{6}$ é formada em Letras Português/Inglês por uma faculdade particular do Distrito Federal e leciona há três anos. Sua história no magistério aconteceu por acaso: apesar do longo tempo de estudo da língua inglesa, ela não concluiu seu curso num Centro Interescolar de Línguas do Distrito Federal. Porém, retomou o estudo da língua após algumas oportunidades de trabalho que exigiam fluência no idioma. Daí até ela se tornar professora foi uma questão de tempo. Diante da necessidade de saber outro idioma, a professora Paula retomou o estudo da língua inglesa num instituto privado de línguas no Distrito Federal e em seguida ingressou na faculdade de letras.

Hoje, ela, que passou por muitas dúvidas sobre qual carreira escolher, se diz realizada e muito motivada em seu trabalho. Ela acredita que a formação continuada do professor é essencial para seu aprimoramento e por isso continua estudando. Todavia, quando lhe perguntamos se ela reflete sobre seu trabalho, ela respondeu que não tanto como deveria, pois o método (do curso) não lhe permite. Dentro das limitações oferecidas pelo método do curso, ela diz que tenta explorar o que há de melhor nele e em si própria. Como exemplo, ela disse que tenta sempre estar se "mexendo", para evitar que a aula seja monótona. No tocante a sua abordagem, ela respondeu que a mesma não condiz com o método que ensina. E mais, disse que na

\footnotetext{
${ }^{6}$ Os nomes usados para identificar os alunos e a professora são fictícios.
} 
instituição na qual trabalha, o método está acima da abordagem. Segundo ela, o material didático dita as regras e normas e o professor é uma marionete, pois só segue os passos estabelecidos no guia do professor. Apesar de a professora sentir-se motivada no seu trabalho, é contraditório seu posicionamento, visto que sua grande queixa é a metodologia do curso.

No contexto pesquisado, o método usado é o audiolingual. Esse método dominou o ensino de línguas até o começo da década de 70. O audiolingualismo fazia uso extensivo de padrões estruturais da gramática contextualizados em diálogos préfabricados e em situações de uso aproximadas ao real. Completava esse método a prática de repetições simples ou com substituições visando a memorização por reforço positivo dos padrões por parte dos aprendentes.

Na sua tese de doutorado, Barbirato (ibid., p.39) assevera que nesse método havia a preocupação de "criar na aula de LE situações de comunicação para os aprendizes". Essa iniciativa "estava diretamente ligada ao objetivo de aumentar o tempo de fala para cada aprendiz", porém esse aumento de quantidade de fala do aprendiz não resultou em um aumento da qualidade (BARBIRATO, op.cit., p.39). Assim, a língua é "apresentada e repetida em drills" (CARDOSO, 2002, p. 69). Os alunos não têm prática livre da língua $\mathrm{A}$ não ser no nível mais avançado quando são usuais as infalíveis aulas de conversação. Eles precisam sempre repetir o que lhes é dito ou formular perguntas que foram feitas por outros. Por outro lado, um ponto forte desse método é o uso da língua-alvo durante as aulas. Almeida Filho (1992) defende "o uso da língua-alvo em sala de aula, como uma forma de incentivar os alunos a fazerem o mesmo".

Dentro do contexto estudado, o método requer uma televisão e um DVD, pois grande parte da aula gira em torno desses dois equipamentos. As lições são apresentadas em formato de diálogos: a professora mostra a história em partes para os alunos, que a acompanham a partir dos desenhos mostrados na tela. Em seguida, a professora explica o que os personagens disseram. Depois de ter explicitado o sentido do enunciado, ela faz algumas perguntas ligadas ao que acabara de mostrar aos alunos com o intuito de averiguar sua compreensão sobre o mesmo. Por exemplo, durante uma de suas aulas, o assunto da história estava ligado a restaurantes. Um dos personagens estava com fome e gostaria de saber se havia um restaurante por perto:

\footnotetext{
7 "Drills" - exercícios de repetição.
} 
Personagem 1: "Boy, I'm hungry. Is there a fast food restaurant around here?"

Personagem 2: "Yes, there is. There is one in the shopping mall."

Personagem 1: "Let's go, I'm starving".

Uma pergunta feita pela professora, após explicar "fast food restaurant" foi a seguinte:

Professora Paula: "Is Mc Donald's a fast food restaurant?"

Alunos: "Yes, it is".

O principal material utilizado durante as aulas é a televisão e o guia do professor. Como já relatamos previamente, todo o conteúdo é apresentado aos alunos através desse aparelho. As provas são baseadas nas lições apresentadas durante as aulas, de forma que o professor precisa seguir passo a passo o guia, caso contrário os alunos não se sairão bem nos resultados finais.

As tarefas de casa também são passadas aos alunos aos poucos, ou seja, eles não têm acesso às lições futuras. Ao término de cada lição do livro, eles recebem somente os exercícios referentes à seção estudada.

Observamos um total de quatro aulas, sendo que, em uma dessas a professora não pôde comparecer, de modo que a observação de aula que ocorreu foi de uma professora substituta. Durante outra aula a professora precisou dar um recado em todas as turmas e, por isso, sua aula durou somente 30 minutos $^{8}$.

No grupo observado, o número de meninos predominava. As meninas participavam atentamente das aulas, porém os meninos sempre eram os que levantavam a mão para responder a uma pergunta ou para serem os assistentes da professora.

É norma do curso que os professores e alunos falem inglês durante as aulas. A professora nos relatou que isso não estava acontecendo durante as aulas, e que seus superiores estavam cobrando a criação de alguma estratégia para remediar o uso da LM durante as aulas. Com o intuito de diminuir o português durante as aulas, a professora sugeriu à turma que aquele que mais falasse português durante as aulas deveria dar-lhe uma fruta na aula seguinte. Segundo ela, depois da criação desse "combinado", os alunos têm usado mais a língua-alvo durante as aulas.

\footnotetext{
${ }^{8}$ Citamos novamente que a professora que acompanhamos também era a coordenadora do curso de línguas. Neste caso ocorreu uma interferência entre o cargo de professora e o de coordenadora do curso.
} 
Vale salientar que apesar de o colégio ter uma grande área, e oferecer aulas do Ensino Básico ao Médio, faltam melhores condições para as salas de aula de LE. A professora que acompanhamos estava dando suas aulas em um espaço pouco adequado para tal fim. Por falta de salas disponíveis, algumas turmas estavam tendo de assistir aulas em duas pequenas salas situadas na biblioteca da escola. Essas salas têm uma mesa redonda no centro, onde alguns alunos podiam colocar seus materiais e se apoiarem para tomar alguma nota. São salas pequenas, desconfortáveis, quentes e sem cadeiras apropriadas para o ambiente escolar.

As professoras de línguas têm recebido reclamações por estarem utilizando aquele espaço: a escola alega que as aulas ali desconcentram os alunos que estão estudando. Perguntamos à professora se a escola lhes ofereceu alguma alternativa, porém a resposta foi negativa. Apesar de a escola ter disponibilizado cinco salas para o curso de idiomas, segundo a professora, somente uma é adequada.

O equipamento de vídeo, essencial para as aulas, funciona perfeitamente. Contudo, faltam nas salas da biblioteca quadros-negros. Em relação a material extra, cópias de exercícios didáticos e outros, a professora diz que a escola é muito prestativa, sendo a única queixa as salas inadequadas. Em relação ao material didático adotado, o curso de idiomas fornece os livros que serão usados pelos alunos durante o ano letivo. Esse material é usado na maior parte do tempo em casa, quando os alunos fazem suas lições. Em classe, o professor pode pedir para os alunos encenarem alguns diálogos que se encontram no livro. Já em relação à produção escrita dos alunos, essa se resume às tarefas de casa. Durante as aulas o enfoque é na produção oral.

O principal material utilizado durante as aulas é a televisão e o guia do professor. Como já relatamos previamente, todo o conteúdo é apresentado aos alunos através desse aparelho. As provas são baseadas nas lições apresentadas durante as aulas, de forma que o professor precisa seguir passo a passo o guia, caso contrário os alunos não sairão bem nos resultados finais.

\section{Análise e discussão dos dados}

Conforme relatamos, esta pesquisa aconteceu numa escola particular, que tem recursos disponíveis para a terceirização das aulas de LE. Essa terceirização permite que os alunos entrem em contato com o método audiolingual, método este que tem a 
preocupação de engajar os alunos na comunicação e diminuir o tempo de fala do professor.

Para analisar a aula representativa do processo instaurado na situação de pesquisa, dividimos a aula em atividades. Tomamos atividade como uma unidade de ação dentro da aula que pode ser reconhecida como tendo começo, desenvolvimento e fecho. Uma atividade se constitui, pois, de ações realizadas na sala ou na suas extensões que reconhecemos como orgânicas e encontráveis na vida fora de sala de aula (ALMEIDA FILHO, 2000, p.29).

Dentro desta pesquisa, buscamos analisar a qualidade das interações na aula típica de inglês dividindo-a de acordo com as atividades "propostas" " . No quadro a seguir é possível visualizarmos como foi feita essa separação:

Quadro 1: Atividades propostas

\begin{tabular}{|c|c|c|c|c|}
\hline Atividade & Descrição & $\begin{array}{l}\text { Duração } \\
\text { (minutos) }\end{array}$ & $\begin{array}{c}\text { Tempo de fala da } \\
\text { professora e do áudio }\end{array}$ & $\begin{array}{l}\text { Tempo de fala } \\
\text { dos alunos }\end{array}$ \\
\hline 1 & $\begin{array}{l}\text { Chegada dos alunos } \\
\text { à sala de aula }\end{array}$ & $2^{\prime}$ & 9 linhas & 24 linhas \\
\hline 2 & $\begin{array}{l}\text { Escolha do } \\
\text { "assistente" }\end{array}$ & $1^{\prime}$ & 5 linhas & 3 linhas \\
\hline 3 & $\begin{array}{l}\text { Organização da } \\
\text { professora }\end{array}$ & $1 '$ & $\ldots$ & 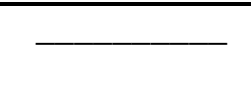 \\
\hline 4 & $\begin{array}{c}\text { Exercício de } \\
\text { repetição }\end{array}$ & 1 ' & 14 linhas & 10 linhas \\
\hline 5 & $\begin{array}{l}\text { Primeiramente } \\
\text { alunos escutam } 3 \\
\text { vezes uma parte do } \\
\text { diálogo. } \\
\text { Em seguida, a } \\
\text { professora faz } \\
\text { perguntas ligadas ao } \\
\text { que os alunos } \\
\text { escutaram para } \\
\text { checar seu } \\
\text { entendimento e } \\
\text { esclarecer dúvidas. } \\
\text { Depois os alunos } \\
\text { repetem } \\
\text { individualmente, a }\end{array}$ & $35^{\prime}$ & 123 linhas & 105 linhas \\
\hline
\end{tabular}

\footnotetext{
9“Propostas", pois não necessariamente todas as atividades que ocorrem durante a aula sejam a partir de propostas. Há atividades que fazem parte do dia a dia da sala de aula e que não precisam ser propostas.

${ }^{10}$ Consideramos o tempo de fala da professora junto com o áudio visto que ambos representariam a "voz" do método. O tempo de fala tanto da professora, do áudio e dos alunos foi medido a partir do número de linhas que cada um teve ao final da transcrição do material.
} 


\begin{tabular}{|c|l|c|c|c|}
\hline Atividade & \multicolumn{1}{|c|}{ Descrição } & $\begin{array}{c}\text { Duração } \\
\text { (minutos) }\end{array}$ & $\begin{array}{c}\text { Tempo de fala da } \\
\text { professora e do áudio }\end{array}$ & $\begin{array}{c}\text { Tempo de fala } \\
\text { dos alunos }\end{array}$ \\
\hline & $\begin{array}{l}\text { mesma sentença, } \\
\text { após escutarem o } \\
\text { áudio. } \\
\begin{array}{l}\text { Após essa repetição } \\
\text { individual, a turma } \\
\text { em coro repete mais } \\
\text { uma vez a frase após } \\
\text { o áudio. }\end{array}\end{array}$ & & & \\
\hline 6 & $\begin{array}{l}\text { Fecho da aula com } \\
\text { despedida }\end{array}$ & 1 ' e meio & 1 linha & 3 linhas \\
\hline
\end{tabular}

O quadro 1 será o ponto de partida da nossa análise. Ele contém a síntese dos principais dados referentes à aula observada. De acordo com ele, vemos que a aula prevista para durar 50 minutos, na verdade durou somente 41 minutos. O tempo perdido se deveu ao deslocamento dos alunos da sua sala de aula até a biblioteca (local da aula). Outra razão para essa redução é a chamada nome por nome realizada na sala principal dos alunos. Dentro desses 41 minutos restantes de aula, pudemos dividir essa "unidadeaula $^{11} "$ em seis atividades.

Tendo observado algumas aulas, notamos que a estrutura delas se mantém constante: tanto na ordem das atividades quanto na duração das mesmas. Em relação a essas atividades que fazem parte da rotina da sala de aula, as atividades um e seis são as melhores representantes. A atividade um, por exemplo, ilustra uma ação cotidiana na sala de aula: a chegada dos alunos, sendo este o momento para eles se acomodarem conversando. Durante esse momento os alunos falam sobre seus combinados, sobre o assunto que estiver chamando mais atenção no dia da aula. Vale ressaltar que as interações que ocorrem durante essa atividade são na LM e que sua duração é muito curta, cerca de dois minutos (aproximadamente 4,8\% da aula total). É interessante também destacar que durante essa atividade os alunos falaram bem mais do que a professora, assim como na atividade seis.

Durante a aula observada, o assunto dos alunos nesse período era a questão das balas. Ao contextualizar o local onde esta pesquisa ocorreu, informamos sobre o combinado entre a professora e a turma: aquele que mais falasse português durante as aulas tinha de dar-lhe uma fruta. Todavia, na semana das nossas observações a professora decidira mudar o trato. Agora o estudante que mais falasse a LM em classe

${ }^{11}$ Unidade refere-se à aula. 
teria de trazer uma balinha para cada um de seus colegas de classe. Como esse acordo havia sido feito recentemente, os alunos falavam sobre isso. Eles questionavam o tipo da balinha, seu tamanho, ou se a pessoa teria se esquecido de trazê-las. A seguir, apresentamos um excerto dessa conversa ${ }^{12}$ :
André: "Cadê o Marcelo com as balinhas?
Carolina: "É vai ter que trazer mais balinhas.
Maria: "É duas balinhas pra cada um na próxima aula".
Francisco: "Professora olha o tamanho da balinha".

Outro assunto de destaque nessa conversa foi iniciado pela professora. Era sobre o novo ventilador:

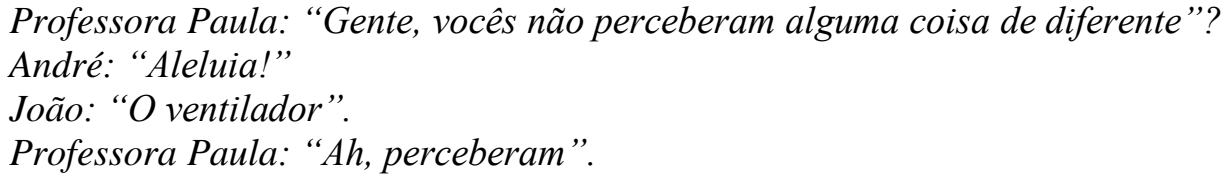

Conforme já mencionado, essa atividade faz parte da rotina diária da aula e os alunos tiveram $72 \%$ da palavra, enquanto que a professora deteve $28 \%$ do tempo. Todavia, ao analisarmos a transcrição da aula, confirmamos que as interações que ocorreram durante essa atividade foram pouco relevantes para o processo de aquisição da LE. Contudo, essa produção de baixo potencial para a aquisição da língua-alvo parece fundamental para as trocas sociais entre e os alunos e entre o alunado e a professora. Esse período da aula representa a transição da LM para a língua-alvo.

A segunda atividade já delimita que o momento é do inglês. Aqui, a professora dá a indicação ao começar a falar na língua-alvo com os alunos. Durante a atividade dois, ela escolhe seu assistente. Essa pessoa fica sendo responsável durante aquela aula por monitorar se seus colegas estão usando a LM. Caso alguém fale português durante a aula, seu nome é anotado numa folha pelo assistente, que o revelará ao final da aula (atividade seis). A seguir apresentamos um excerto dessa delimitação feita pela professora:

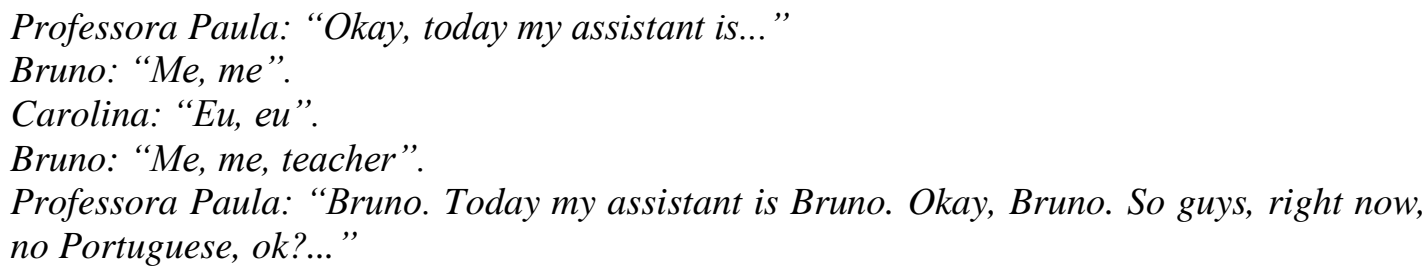

${ }^{12}$ Em anexo há uma tabela com as abreviações utilizadas neste artigo. 
A duração dessa atividade é de um minuto (cerca de $2,43 \%$ da aula total) e o tempo de fala dos alunos é bem menor do que o da professora (37,5\%). Conforme citado anteriormente, o objetivo dessa atividade é fazer a transição da LM para a língua-alvo. Em relação à relevância da mesma consideramo-la importante por marcar o uso da línguaalvo durante a aula (apesar de sua curta duração).

A próxima atividade (três) seria uma espécie de "entre-atividade""13, ou seja, tratase de um momento de organização da professora. Aqui nem ela nem os aprendizes se comunicaram, o que reflete sua irrelevância para a aquisição da LE. Essa atividade durou cerca de um minuto $(2,43 \%$ da aula toda).

Com a atividade quatro iniciam-se os exercícios de repetição. Durante essa atividade os alunos revêem o conteúdo da aula anterior rapidamente. A professora, com o apoio do aparelho de televisão e de DVD, mostra aos alunos o diálogo já apresentado, o qual eles escutam e repetem. Assim como as duas atividades anteriores, essa também teve uma curta duração, de um minuto, ou aproximadamente $2,43 \%$ da aula. Aqui os alunos falaram $41,66 \%$ do tempo e a professora $58,33 \%$. Em relação à sua importância para a aquisição da LE, ela representa uma atividade altamente manipulada, na qual se nota um alto grau de controle por parte da professora e uma participação muito previsível e pobre por parte dos alunos. O excerto a seguir ilustra uma dessas repetições:

TV: "Is there a fast food restaurant around here?"

Alunos (as): "Is there a fast food restaurant around here?"

Professora Paula: "Listen again, guys".

A atividade seguinte (cinco) foi a de mais longa duração: 35 minutos, ou seja, $85 \%$ da aula. Nessa atividade estão embutidos certos passos constituintes de forma que a segmentaremos em partes menores. A atividade principal era escutar e repetir o diálogo apresentado no vídeo. Inicialmente os alunos escutam cada fala dos personagens três vezes seguidas (passo um). Depois a professora faz perguntas sobre aquela fala para checar a compreensão dos aprendizes e esclarecer quaisquer dúvidas que surjam (passo dois). Em seguida, os alunos escutam a mesma sentença e a repetem individualmente (passo três). Assim que todos terminam essa repetição individual, a professora repete pela última vez a mesma sentença, a qual todos os alunos repetem em coro (passo quatro). A professora e seus alunos repetem esse processo seis vezes durante a atividade.

\footnotetext{
13 "Entre-atividade" refere-se exatamente a este período durante a aula, quando a professora finaliza uma atividade, mas sem ainda ter iniciado outra.
} 
O tempo de fala da professora e dos alunos foi respectivamente de 53,94\% e $46,05 \%$ durante a atividade cinco, levando em consideração que no primeiro passo os alunos se mantiveram passivos, tão somente escutando. Durante o passo dois, os alunos tiveram a possibilidade de responder às perguntas que lhes haviam sido feitas. No entanto, assim como já asseverado, as perguntas formuladas eram todas relacionadas ao contexto do diálogo e aos personagens. O tipo de interação foi marcado pelo modelo: professor inicia - aluno responde - professor avalia a resposta do aluno. O próximo excerto ilustra bem essa questão:

Professora Paula: "Is this a hamburger or a ham and cheese sandwich, Estela?" (Professora inicia)

Ana Maria: "Sandwich". (Aluna responde)

Professora Paula: "Complete answer". (Professora avalia)

Ana Maria: "That is a ham and cheese sandwich".

Professora Paula: "Yes, good, okay and..."

No passo três os alunos escutavam o áudio e depois repetiam individualmente cada fala dos personagens. Aqui vários deles apresentaram dificuldades ao pronunciar algumas palavras. A professora sempre enfatizou e corrigiu os erros de pronúncia. Alguns alunos tiveram problemas ao pronunciar a palavra "hamburger". Muitos acentuavam a segunda sílaba, sendo que a primeira seria a sílaba tônica.

O passo quatro é o último no processo que recomeça com cada nova fala de um dos personagens. Ele encerra as repetições daquela sentença com uma última repetição em coro em uníssono.

Em seguida, a atividade seis sinaliza o término da aula. Se a atividade dois simboliza a transição da LM para a língua-alvo, aqui temos o processo inverso: da línguaalvo para a LM. Essa atividade durou cerca de 1 minuto (2,43\% da aula) e somente os alunos falaram entre si. A interação que ocorreu foi em português. A atividade seis faz parte da rotina da aula e marca a despedida dos alunos. Aqui, a despedida durou menos de um minuto e os alunos usaram a língua-alvo. Nessa última fala dos alunos, várias falas se misturaram.

Professora Paula: "Bye-bye. See you next class".

Alunos: "Bye-bye, see you".

Os turnos de fala dos alunos e da professora se equivaleram em número. Os alunos falaram quase tanto quanto a professora (49\%) embora ela seja só uma pessoa enquanto 
eles são doze.

Quanto ao modelo principal de interação, este é marcado pelo controle da professora, visto que é ela quem inicia os turnos e dá a avaliação após a resposta dos alunos. Apesar do grande número de oportunidades que os alunos tiveram para se expressar, essas oportunidades já vinham com modelos de respostas previamente estabelecidos que os alunos deveriam acatar. Destarte, as interações entre os alunos e entre a professora e os estudantes foram fruto de situações imaginárias e artificiais nas quais houve espaço muito reduzido para se falar de si próprio e de questões reais envolvendo os aprendizes.

\section{Considerações finais}

A partir da análise feita, concluímos que a interação presente neste contexto é uma interação artificial, controlada e centrada no livro didático e na figura da professora. Vimos que as interações dentro do contexto discutido são pré-fabricadas, de pouca qualidade, artificiais e "engessadas" Apesar do alto índice de turnos de fala dos alunos, a interação presente é muito manipulada e pré-estabelecida, isto é, o aluno não pode ir além do que está estabelecido pelo método no livro didático. E mais, os alunos não iniciaram turnos de fala, cabendo isso tão somente à professora. Ou seja, não houve espaço para a expressão espontânea ou não-ensaiada.

Convém frisar que nos surpreendemos ao encontrar dentro do ensino regular uma escola que estivesse trabalhando a LE em níveis da oralidade. Apesar de o ensino ser baseado na abordagem tradicional gramatical, devemos reconhecer esse fato como um sinal positivo em comparação com as aulas que enfocam apenas estruturas gramaticais dadas em LM.

Vimos também que um método pode estar acima do professor e ser um fator determinante para o tipo de interações que serão estabelecidas. Inclusive que o material didático que deveria servir como material de referência, de apoio para o professor, acaba por tornar-se o principal instrumento a ser usado durante as aulas. Há contextos de ensino onde a abordagem do professor tem de ser deixada de lado se ele quiser manter seu emprego. Esta questão sobre a prática que se faz e a que nós dizemos fazer (ou gostaríamos de fazer) muitas vezes fica no plano do ideal pela falta de perspectivas de mudança. 
Tivemos algumas limitações no decorrer deste estudo. Conforme indicamos anteriormente, nem todas as aulas que observamos foram lecionadas pela mesma docente, o que pode ter sido um fator limitante na escolha da aula "típica". O contexto observado foi um recorte dentre os vários contextos possíveis para análise da qualidade das interações. Acreditamos que há outros ambientes onde podemos encontrar interações com qualidade mais alta que permita aquisição da nova língua.

Esperamos que esta pesquisa possa contribuir para os estudos de aquisição de segunda língua (ASL), mas principalmente para incentivar professores de línguas a analisar e refletir sobre a sua prática pedagógica e lançar um olhar crítico sobre a mesma.

\section{Referências}

ALMEIDA FILHO, José Carlos P. (Org.). A abordagem orientadora da ação do professor. In: Parâmetros atuais para o ensino de português língua estrangeira. Campinas: Sapec Pontes, 1997, p. 13-28.

Editores, 1999.

O professor de língua estrangeira em formação. Campinas: Pontes

Interação e interdisciplinaridade no ensino de línguas em contexto de LE. Relatório de pesquisa FAPESP. São Paulo, 2004.

Pontes, 2005.

Lingüística aplicada, ensino de línguas e comunicação. Campinas:

ALMEIDA FILHO José Carlos P.; BARBIRATO Rita C. Ambientes comunicativos para aprender língua estrangeira. Trabalhos em Lingüística Aplicada, v. 36, p. 23-42, 2000.

ALMEIDA FILHO, José Carlos P.; CUNHA, Maria J. C. A produção de projetos iniciais sobre o processo de ensino-aprendizagem de línguas. In: Projetos iniciais de pesquisa na área de português para falantes de outras línguas. Brasília/Campinas: Editora da UnB e Pontes, 2007.

BARBIRATO, Rita C. Tarefas geradoras de insumo e qualidade interativa na construção do processo de aprender língua estrangeira em contexto inicial adverso. 2005. Tese (Doutorado em Linguística Aplicada) - Instituto de Estudos da Linguagem, Universidade Estadual de Campinas, Campinas, 2005.

CARDOSO, Rita C. T. O imaginário do comunicativismo entre professores de LE/ inglês - e sua confrontação com a teoria externa. Tese (Doutorado em Letras) - Faculdade de Ciências e Letras, UNESP, Assis, 2002.

MOURA, Elenir V. X. O nível de robustez interacional e a interferência das abordagens 
de ensinar e de aprender em aulas de língua estrangeira. 2005. Tese (Doutorado em Linguística Aplicada) - Instituto de Estudos da Linguagem, Universidade Estadual de Campinas, Campinas, 2005.

PRABHU, N. S. A dinâmica da aula de língua. Tradução de Almeida Filho, J. C. P. e Cardoso, R. C. T. Contexturas, n. 5, 2001. 